\title{
NAS TEIAS DA ECONOMIA: o papel das redes sociais e da reciprocidade nos processos locais de desenvolvimento
}

\author{
Guilherme Radomsky* \\ Sergio Schneider**
}

\begin{abstract}
Resumo: O trabalho aborda o tema das redes sociais de trabalho sob o ângulo das relações de reciprocidade. A partir de um estudo de caso no município de Veranópolis, Rio Grande do Sul, o artigo procura compreender a importância das relações de reciprocidade para a constituição de redes de trabalho ligadas a comerciantes, a indústrias de fusão de aços e a indústrias de calçados e artigos esportivos. Pretende-se demonstrar que, apesar de uma origem social comum, as diferentes redes de trabalho apresentam distintas características no que diz respeito a formas de trabalho, modo de operação e regulação da concorrência entre os empreendimentos. No caso estudado, o conjunto de relações em rede é responsável pelo dinamismo do mercado de trabalho e pela diferenciação da economia local, uma vez que articula os atores que compõem o tecido social e exerce efeitos relevantes para o desenvolvimento do território como um todo.
\end{abstract}

Palavras-chave: redes sociais, reciprocidade, território.

\footnotetext{
* Sociólogo, mestre em Desenvolvimento Rural pela Universidade Federal do Rio Grande do Sul (UFRGS) e integrante do Grupo de Estudos e Pesquisas sobre Agricultura Familiar e Desenvolvimento Rural (GEPAfDr). Desenvolve pesquisas sobre redes sociais, relações de reciprocidade e economias locais. E-mail: radomsky@universia.com.br

* Sociólogo, mestre em Desenvolvimento Rural pela Universidade Federal do Rio Grande do Sul (UFRGS) e integrante do Grupo de Estudos e Pesquisas sobre Agricultura Familiar e Desenvolvimento Rural (GEPAfDr). Desenvolve pesquisas sobre redes sociais, relações de reciprocidade e economias locais. E-mail: radomsky@universia.com.br
}

Arquivo recebido em 16 jan. 2007 e aprovado em 15 abr. 2007. 


\section{Introdução}

É pouco provável que se encontre na Sociologia contemporânea um conceito que seja capaz de referir-se às mudanças societárias em curso de modo tão adequado como o de redes. A emergência e a rápida difusão da noção de redes parece estar conectada tanto ao processo de globalização como à proliferação massiva das tecnologias de comunicação e informática. Por isso, não surpreende que o livro de Castells (1998), A sociedade em rede, tenha se tornado um quase best-seller entre as obras de interpretação das mudanças sociais recentes. Na verdade, talvez seja possível dizer que a noção de rede, neste caso, alçou-se a um sentido alegórico, tornando-se a imagem e a representação emblemática dos processos sociais mundializados.

No entanto, mais sintomático parece ser o movimento reverso que ocorre simultaneamente a este e que passa a requerer legitimidade para o uso da noção de rede. Para além da sua significação vinculada à globalização, a noção de rede passou a atrair a atenção de pesquisadores em ambientes acadêmicos que estavam preocupados em compreender os movimentos e as articulações que ocorrem em nível local. É como se as teorias pudessem ser renovadas a partir de um conceito que procura desvendar algo não necessariamente novo nas relações sociais que são localizadas, e que podem ser potencializadas pelo uso da noção de rede.

Segundo Scherer-Warren (2005), a história do conceito de rede nas Ciências Sociais remonta aos escritos de Saint-Simon no século XIX, mas ganha projeção em meados do século XX com os estudos de Radcliffe-Brown (1952), Barnes (1987), Mayer (1987) e outros. Entretanto, estes estudos enfatizavam mais o caráter das relações e suas configurações em rede do que propriamente a territorialização das interações - e sua importância -, ou seja, parecia não haver um "problema" (no sentido sociológico) entre as relações local versus global. 
A utilização do conceito de redes entre os estudiosos do desenvolvimento é ainda mais recente e difusa. Com algum esforço é possível dizer que os estudos recentes sobre capital social, território e sobre a idéia de enraizamento (embeddedness) de Granovetter(1985), levaram os Cientistas Sociais a pensar além das noções de estrutura social e funções de causalidade. Ocorre que estas perspectivas não se revelavam satisfatórias para compreender e explicar os modos de interação social que mudam de forma e conteúdo em face das tecnologias de propagação da comunicação humana (Internet, etc.). Apesar de estas tecnologias criarem novas sociabilidades, o fato é que passam a exigir e a retomar velhos mecanismos de controle e poder.

Este trabalho se inscreve nesse quadro de referências, focalizando os processos de interação social onde as relações entre o rural e o urbano são expressivas e em que predomina a agricultura familiar. O local onde foi realizado o estudo - o município de Veranópolis, no Rio Grande do Sul -, possui uma dinâmica econômica significativamente caracterizada por uma teia de relações entre empresas, estabelecimentos comerciais, unidades agrícolas e pessoas, e essa dinâmica bem poderia ser interpretada por meio do conceito de redes. Aqui também a especificidade local precisou ser, de certo modo, contrastada com os níveis de escalas superiores (regional, nacional e global) para que o olhar pudesse fazer emergir esta configuração reticular territorializada.

Passando a investigar mais precisamente o problema de pesquisa, à medida que se descobria o modo de funcionamento dessas redes, verificava-se que as relações de proximidade eram fundamentais para a sua constituição e operação. E a proximidade entre os atores sociais se mesclava, muitas vezes, com atributos tais como o parentesco ou a amizade. Portanto, a complexidade é que a rede pode envolver atores sociais heterogêneos, ligados por características diversas, tais como: o parentesco, a amizade, a etnia 
e a identidade. Em meio a esse processo, um aspecto chamou mais a atenção do que todos os outros: o papel das relações de reciprocidade para a manutenção dos laços que fundamentam as redes. A noção de reciprocidade parecia explicar a trama que se sucedia, pois uma economia moral fornecia as bases do funcionamento da economia material, recursos sociais disponíveis no território para aqueles que partilham os códigos sociais e que estão inseridos na história local. Desse modo, a questão a procurar responder seria: como as relações de reciprocidade, proximidade, amizade e parentesco podem ser constituintes de redes sociais e econômicas e capazes de estimular o desenvolvimento? Entretanto, as primeiras investidas a campo mostraram que a diversidade de formas pelas quais estas redes de relações se apresentam era expressiva. Assim, mesmo havendo um núcleo comum que estrutura a natureza dos vínculos sociais locais, este se aproxima mais de uma raiz originária histórica, ainda bastante presente, que não chega a extinguir as particularidades e diferenças que as distintas redes conformam.

Assim sendo, o presente trabalho pretende mostrar que, apesar de uma origem social comum, as diferentes redes de trabalho apresentam distintas características no que diz respeito a formas de trabalho, modo de operação e regulação da concorrência entre os empreendimentos. Como conseqüência, este estudo também tem a intenção de mostrar que o conjunto das relações em rede fornece dinamismo ao mercado de trabalho, exercendo importantes efeitos para o desenvolvimento do território.

A fim de entender os processos sociais em torno das relações em rede e por meio da reciprocidade, este estudo centrou-se em três redes de trabalho de Veranópolis ligadas aos comerciantes de frutas (fruteiros), às indústrias de fusão de aços (microfusão) e às indústrias de calçados e artigos esportivos. A partir da comparação entre as três redes acima descritas, a intenção é que se possa caracterizar e analisar as particularidades sociais e econômicas existentes no 
local, bem como mostrar a dinâmica do mercado de trabalho e do desenvolvimento no território.

Os procedimentos metodológicos utilizados neste estudo de caso foram as técnicas e os métodos qualitativos de análise, através de entrevistas semi-estruturadas e da observação. Foram ouvidos vinte informantes, cuja amostra não-aleatória compreendeu diferentes grupos e posições sociais na sociedade local. Apesar de haver uma pré-definição da amostra, outros componentes foram incluídos ao longo da pesquisa devido às descobertas no campo, segundo sugestão metodológica de Flick (2004, p. 79). Por esta razão, a técnica de observação foi intercalada com as entrevistas, pois, à medida que se observavam os atores sociais em interação e eram entrevistados os mais relevantes para a pesquisa, a amostra gradualmente se tornava mais rica. As entrevistas foram analisadas com o software de análise qualitativa NUD*IST.

O trabalho está dividido em quatro partes, sendo esta introdução a primeira. Na segunda parte, abordam-se referenciais teóricos que embasam a análise. $\mathrm{Na}$ terceira parte apresentam-se o local do estudo e os resultados do trabalho, com a análise das três redes acima mencionadas. Na quarta e última parte tecem-se algumas considerações finais do estudo.

\section{Dádiva, reciprocidade e redes: leituras e aproximações}

Numa das leituras contemporâneas mais instigantes feitas acerca do Ensaio sobre a dádiva de Marcel Mauss (1974), Alain Caillé (1998a, 1998b) procurou acentuar a dimensão ética e antiutilitarista contida no fenômeno da dádiva, que o diferencia das exegeses empreendidas por autores como Lévi-Strauss (1974) e Bourdieu (1996a). Para isto, Caillé insiste no aspecto da gratuidade do dom, e define dádiva como qualquer ação sem expectativa 
imediata ou certeza de retribuição, com objetivo de "[...] criar, manter ou reproduzir a sociabilidade, comportando, portanto, uma dimensão de gratuidade" (Caillé, 1998b, p. 76 apud Sabourin, 2003, p. 1) e reciprocidade como a reprodução da própria dádiva. Desde Mauss, o horizonte analítico da teoria das trocas na vertente francesa apostou fortemente que os laços sociais se fundamentam em trocas (não apenas econômicas). Portanto, dádiva e reciprocidade são momentos que se seguem num mesmo ato, e Mauss observou que na troca há sempre três momentos que se revertem no princípio da ação recíproca - dar, receber, retribuir. A troca não seria somente uma permuta de produtos, ela carrega a potencialidade da sociabilidade humana, sobre a qual se fundam a solidariedade, a integração social e as obrigações mútuas.

Caillé escava as camadas em que estão petrificadas as diferentes interpretações sobre a obra de Mauss e retorna a uma teoria que permaneceu confinada à Antropologia, sobretudo aos estudos sobre sociedades tradicionais. ${ }^{1}$ Não é porque Mauss observara o fenômeno primordialmente a partir dos trobriandeses da Polinésia (por meio dos textos de Malinowski) e das sociedades indígenas no noroeste da América do Norte que estas práticas seriam localizadas ou primitivas. Ao contrário, desde Durkheim, a análise das sociedades (chamadas de) simples tem a função sociológica de lançar luzes sobre as (chamadas de) complexas. E o próprio Mauss faz uma consideração fundamental na parte final do Ensaio sobre a reciprocidade nas diferentes sociedades, afirmando que "uma parte considerável de nossa moral e nossa vida permanece sempre nesta atmosfera da dádiva, da obrigação e, ao mesmo tempo, da liberdade" (Mauss, 1974, p. 185).

Além das considerações preceituais que a reciprocidade impõe, ou seja, que fundamentos éticos o entendimento sobre a dádiva e a retribuição podem amparar as relações sociais (e econômicas) humanas, Caillé também ponderou sobre as conseqüências para 
uma teoria do social que este pensamento oferece. Relendo Mauss, Caillé (1998a) sustenta que a dádiva é simultaneamente obrigação e liberdade. É na “aposta da dádiva” que os atores sociais manterão suas ligações, mas a dádiva não é norma, "[...] pois é, de fato, unicamente numa situação de incerteza estrutural que o problema da confiança e da tessitura do laço social se coloca [...]” (Caillé, 1998a, p. 15). $\mathrm{O}$ autor atenta para o fato de que, entre os atores da troca, há uma procura pela retribuição o mais depressa possível, pois a obrigação mútua mantém em relação aqueles que estabelecem esta troca. Entretanto, Caillé persegue uma conceituação da dádiva que procure vencer pólos redutores tais como a preponderância da obrigação, de um lado, ou da espontaneidade, de outro; do instrumentalismo ou do prazer, dos atos interessados ou desinteressados. Propõe que o conceito de dádiva é inaplicável se não houver tudo isso: obrigação, liberdade, interesse, espontaneidade e prazer.

Assim, o problema da reciprocidade como constituinte da relação social é trabalhado por Mauss e Caillé a partir de dois aspectos fundamentais: o elemento simbólico e a materialidade do ato. Estes dois aspectos não são excludentes e separados, eles compõem o ato da troca, que é uma ação objetiva. ${ }^{2}$

À medida que estes laços sociais se constituem com extensões ampliadas, não somente ligando indivíduos em relações diádicas, a noção de rede passa a ser um recurso explicativo para um conjunto específico de relações numa determinada sociedade, tal como argumentado em Radomsky (2006). Esta perspectiva, trabalhada no pensamento social francês apenas recentemente, encontrou espaço de profícuo desenvolvimento nas Ciências Sociais britânicas desde os anos 1940. Contrapondo-se ao ponto de vista estruturalfuncionalista de Radcliffe-Brown, para quem rede era a estrutura da sociedade, Barnes (1987) definiu rede como um conjunto de relações interpessoais concretas que vinculam indivíduos a outros. Ocorre que a reciprocidade pode sedimentar as relações sociais, pois vincula 
os sujeitos por meio de suas condutas (isto é, das obrigações morais e da liberdade do agir recíproco) e da carga simbólica que contém o dar e o retribuir. Porém é incapaz de explicar, por si só, porque certas coalizões interpessoais são mais importantes que outras em dada sociedade, ou qual o papel da posição dos sujeitos para suas interações. ${ }^{3}$ Além disto, partindo de outro prisma, Granovetter (1973) sugeriu que a noção de rede é um recurso metodológico quando a análise sociológica procurar lidar com as interfaces dos níveis micro e macrossociológico.

Assim, Barnes e outros antropólogos como Mayer (1987) e Boyssevain (1987) preservam a noção de rede rejeitando a teoria estrutural-funcionalista de Radcliffe-Brown. Distintamente da tradição francesa, a linha de pensamento que guia esses autores tende a enfatizar os aspectos estratégicos da ação, concedendo menos importância ao caráter simbólico das relações sociais. As redes, neste caso, são constituídas como resultados de estratégias, e são recursos dos indivíduos, em oposição ao constrangimento normativo do sistema social sugerido pelos funcionalistas. Esse aspecto é bastante relevante porque a idéia de redes, nesta perspectiva, pode envolver a intencionalidade (uma razão finalista), fato que pode expressar uma estratégia. Pode-se argumentar, entretanto, que ela também é mediada por esquemas simbólicos e culturais, pois no grupo social nem todos os indivíduos são passíveis de formar alianças.

Estudos recentes sobre redes sociais têm avançado em questões centrais da teoria sociológica, tais como as relações entre a ação dos sujeitos, sua racionalidade e as estruturas da sociedade. Algumas destas pesquisas mostram que a circulação de idéias, bens, poder e informação é estruturada pelas relações que mantêm os indivíduos, as organizações e as entidades (Marques, 2006, p. 19). Do ponto de vista do poder, Marques ainda sugere que esta perspectiva estaria contribuindo para o entendimento da importância das 
posições e das relações sociais para as escolhas dos indivíduos, bem como suas alianças e sua capacidade de acessar bens ou pessoas.

Outros autores, tais como Lowe et al. (1995), Murdoch (2000) e Long (2001), preocupados com a capacidade heurística do conceito de rede para a compreensão dos processos sociais de desenvolvimento local, defendem a idéia de que este referencial possibilita entender tanto redes que se formam num território, como também as que o extravasam. Sob este prisma, as redes complexificam a noção de território, uma vez que sua flexibilidade pode constituir ou desconstruir territorialidades (ligando pontos descontínuos no espaço), e com isso também a imagem pela qual se representa o espaço. No Brasil, o trabalho de Mior (2006) defende que o conceito de rede permite mostrar a crescente integração entre o rural e o urbano. Nessa abordagem, é possível distinguir processos de articulação do local e do global em redes verticais e horizontais, ou seja, as cadeias de commodities que vinculam a agricultura a outros setores econômicos e as redes territorializadas em que a inovação e a aprendizagem local são essenciais (Mior, 2006, p. 285).

A literatura sobre o tema das redes é bastante ampla e não pode ser esgotada neste artigo nem por estes autores, mas vale destacar que a perspectiva adotada neste trabalho procura dialogar com estas duas concepções sobre a natureza do vínculo social, a reciprocidade e a rede. Isto se tornou fundamental, pois as interpretações sobre os fatos econômicos que se ancoram na noção de reciprocidade, geralmente, fazem menção à manutenção dos laços sociais por um conjunto de atores sociais. ${ }^{4}$ Assim, as redes seriam a materialização das interações empreendidas coletivamente.

No tópico a seguir, procura-se restringir a análise sobre o tema da reciprocidade e das redes sociais enfocando estas duas noções em conexão com a dimensão econômica das sociedades. 


\section{Reciprocidade e economia: Karl Polanyi e os avanços da Nova Sociologia Econômica}

Observando-se os escritos de autores contemporâneos sobre as relações existentes entre a economia e as instituições de uma sociedade, torna-se bastante difícil não se surpreender com as muitas referências a um dos primeiros autores a analisar esta questão, Karl Polanyi. Pode-se afirmar que sua obra foi dedicada a pensar os aspectos históricos, sociais e institucionais sob os quais as sociedades organizam suas economias. Em um dos seus textos mais conhecidos, Polanyi (2000) procurou demonstrar que nenhuma sociedade não-capitalista conheceu um tipo de sistema econômico baseado no livre intercâmbio, ou seja, totalmente regulado por mercados. $\mathrm{O}$ intercâmbio é apenas um dos três princípios que este autor postulou para explicar as economias, os outros dois são a redistribuição e a reciprocidade. $\mathrm{O}$ conceito de reciprocidade em Polanyi é vinculado à idéia de simetria e a reciprocidade, na ótica deste autor, é a movimentação entre pontos correlativos de grupos sociais simétricos (Polanyi, 1976, p. 296).

O que deve ser realçado na presente análise é que a idéia de uma sociedade regulada por mercados, para Polanyi, fundamenta-se no livre intercâmbio de mercadorias (e força de trabalho), um sistema de impessoalidade. É este tipo de sociabilidade que se estabelece no capitalismo, na qual a economia deixa de ser submersa na sociedade e se particulariza numa esfera do social. Polanyi percebeu que à medida que a mercantilização avançava, enfraquecia-se a reciprocidade e a redistribuição. Contudo, como acreditava na necessidade de regular e frear este processo (o moinho satânico) através de instituições e do Estado, observou que não havia impedimentos para a coexistência entre formas de troca por reciprocidade e por intercâmbio.

Para Polanyi (2000, p. 75), em todas as sociedades nãocapitalistas os princípios da vida econômica são institucionalizados 
através de uma organização social, isto é, eles são disciplinados por padrões específicos de comportamento. Vale ser ressaltado que em seus escritos aparece a tese de que a sociedade mantém-se no direito de regular os mercados e não o inverso.

Nesse sentido, para Polanyi, o "ator econômico" é uma categoria possível apenas no sistema capitalista de relações sociais. Pesquisadores que procuraram dar continuidade às suas pesquisas se depararam com um modelo teórico no qual este ator seria brutalmente particularizado quando em seu contexto de ação econômica, e deixaria o mundo da impessoalidade quando estivesse em outro contexto de ação (não-produtivo). Conseqüentemente a dádiva e a reciprocidade seriam categorias pré-históricas, assim como as sociedades em que elas ocorriam, ou absolutamente "antieconômicas". A alternativa a isto seria considerar a importância da reciprocidade mesmo num ambiente econômico transformado historicamente, como no capitalismo, com a instauração da impessoalidade, mas não a sua completude, portanto sem o aniquilamento das relações de proximidade entre os atores sociais, seja em contextos produtivos seja em não-produtivos.

Se, por um lado, Polanyi sugere que, nas sociedades reguladas pelos princípios de redistribuição ou reciprocidade, o intercâmbio livre aparece, muitas vezes, de forma residual; de outro, há pouco espaço para considerar as formas de economia de redistribuição e de reciprocidade depois que o capitalismo instaura os mercados livres e as práticas de intercâmbio.

A crítica da Nova Sociologia Econômica incidiu exatamente neste aspecto e, ironicamente, amparou-se de forma crucial no conceito de submersão de Polanyi. Esta perspectiva procura se diferenciar da Sociologia Econômica Clássica exatamente no ponto em que Polanyi reconheceu a existência de mercados autoreguláveis. Num artigo recente, por exemplo, Abramovay (2004, p. 
55) reconhece que até mesmo a "auto-regulação depende da própria maneira como a interação social ocorre". Abramovay sugere que a impessoalidade dos mercados existe, mas as interações concretas e localizadas são fundamentais para suas dinâmicas. As formas de reciprocidade podem influenciar significativamente as relações econômicas.

Um dos avanços mais importantes desta corrente de pensamento foi trazer a idéia de enraizamento ou submersão (embeddedness) para o interior das formações sociais capitalistas e sugerir que nelas, os vínculos concretos, as relações de proximidade, a racionalidade limitada pelo contexto (como salientou Wanderley, 2002) e a atmosfera cultural da sociedade são essenciais para as relações econômicas.

É neste sentido que a noção de rede se torna um importante referencial a partir do qual analisar as relações sociais e econômicas num dado contexto. Se os mercados são constituídos por atores sociais que estabelecem interações específicas e concretas, as posições dos indivíduos, as relações de proximidade e os vínculos sociais que possuem determinada história personalizam os mercados. Essa configuração faz com que os mercados não sejam anônimos, ao contrário, conhecer as pessoas faz parte das ações que se realizam neste espaço social, e, dessa maneira, há a possibilidade de se conformarem redes.

A tese de Granovetter (1973) sobre as redes interpessoais que dão espessura aos mercados de trabalho adverte sobre este mesmo aspecto, e torna pouco plausível a idéia de impessoalidade ${ }^{5}$ nos mercados. Também reside neste aspecto, referente às redes de ligações pessoais, a importância dos trabalhos de Marques (2006) sobre as políticas urbanas e de Long (2001) sobre o meio rural peruano. No caso de Granovetter, ele mostrou a importância dos laços sociais para a obtenção de empregos nos mercados de trabalho, 
isto é, são os laços numa cadeia de relações os responsáveis pelo sucesso. "Conhecer" pessoas é o que constitui a rede, portanto as formas de relação social são concretas e permeadas de atitudes recíprocas - de coesão social (Granovetter, 1973, p. 1373). Uma das questões mais interessantes levantadas no trabalho deste autor é a que mostra a "força que existe nos laços fracos". Numa rede de pessoas, há ligações de proximidade (laços fortes), mas, muitas vezes, a mobilidade no emprego ocorre por meio de pessoas que são "conhecidos de conhecidos" ou "amigos de amigos".

Algumas das questões que emergem a partir destas considerações a respeito da formação de redes de reciprocidade seriam: em que medida estas relações se situam em um determinado espaço? E a dimensão do tempo, qual seu papel?

Território e relações sociais: mercados como construções sociais num espaço

Arnaldo Bagnasco e Carlo Triglia, dois pesquisadores italianos interessados nos estudos sobre mercados e sociedade, observaram a importância das construções históricas e sociais para os mercados. Em seu estudo sobre a Terceira Itália, descobriram que os mercados não apenas são influenciados pela dinâmica das interações concretas e pela personalização dos laços sociais, mas que estas duas dimensões são construções históricas, assim como os mercados. O elemento espacial se tornou central para a análise dos autores visto que um tipo de configuração de relações sociais é responsável, no tempo, por aquilo que eles denominaram de formação regional (Bagnasco, Triglia, 1993). Nesta formação social e regional analisada, a reciprocidade não desaparece ao longo do tempo, mas funcionará como reguladora das relações mercantis, principalmente nos períodos de crise. 
Portanto, nas transformações sociais e históricas, há a continuidade de certas características coletivas, atributos de uma formação regional. No exemplo dos autores, na passagem de uma sociedade agrícola para uma industrializada, permanecem sinais de continuidade histórica, como a manutenção das relações de reciprocidade. A maneira como as empresas se vinculam, as formas de reciprocidade nas relações, o papel da família e das instituições políticas aparecem no trabalho dos autores como elementos culturais de expressiva capacidade para estruturar as relações econômicas numa região. Bagnasco e Triglia (1993, p. 38), insistindo no aspecto cultural que marca a construção dos mercados, mostram que um conjunto de relações sociais particulares contribuiu para "a emergência de uma formação social específica".

Uma das facetas pelas quais se pode estabelecer um nexo entre o trabalho de Bagnasco e Triglia com o caso estudado neste trabalho, Veranópolis, é o papel da família nos empreendimentos. Tal como na Terceira Itália, Veranópolis tem sua origem numa sociedade dedicada à agricultura, na qual a família rural tinha um papel fundamental para gerir sua unidade produtiva. $\mathrm{Na}$ transformação social ao longo do século XX, a família não deixa de ser o sustentáculo dos empreendimentos que se espalham pelo meio urbano, caracteristicamente empresas dedicadas a atividades não-agrícolas. Para os autores, a família detém um saber sobre a gestão e a organização do trabalho que é transmitido a cada geração, independentemente das unidades produtivas serem propriedades agrícolas ou empresas. Logo, as empresas familiares, que preservam relações sociais de interconhecimento e proximidade, se mantêm também em função de os mecanismos de reciprocidade e de autoridade permanecerem presentes.

O que os raros estudos sobre reciprocidade e sua vinculação ao tema do desenvolvimento tentam mostrar é que existe uma externalidade positiva quando a intensidade dos laços sociais de 
proximidade auxilia na promoção de sinergias locais entre os atores sociais. A profusão das pesquisas em torno do conceito de capital social indica que o assunto é relevante, embora esta perspectiva tenda a incidir em dois aspectos que aqui se considera pouco promissores. O primeiro se traduz na visão apenas positiva destes laços, desconsiderando aquilo que a dádiva tem de negativo: a formação de relações assimétricas e a dádiva agonística, tal qual Bourdieu (1996a, 1996b) mostrou. O segundo está ligado à crença exacerbada na capacidade "natural" de que toda região ou grupo social pode gerar capital social, e que somente precisaria ser estimulado. $\mathrm{Na}$ contramão desta corrente, Caillé insiste que a dádiva é o nunca saber se haverá a retribuição, o jamais entender se ela é mais ou menos espontânea, é a incerteza estrutural do ato. Portanto a reciprocidade traduz o terreno movediço que é a relação humana.

No entanto, há que se considerar que as sinergias espacialmente localizadas muitas vezes mantêm relação com uma história de formas de reciprocidade no tecido social. E esta característica da proximidade influencia a sua dinâmica. Por esta razão, a discussão sobre o desenvolvimento pode tomar o ponto de vista das redes sociais, pois estas incorporam a noção de território para enfatizar as ações simultâneas e localizadas que permitem o desenvolvimento se instituir sob o ângulo dos atores sociais.

Bottazzi (1994) mostra que o fato de recorrer à espacialidade como recurso de análise das relações sociais significa reconhecer que o espaço possui uma dimensão sociocultural cujo papel vem a ser central. Ele se diferencia precisamente por que as relações estabelecidas aí são particulares, pois o espaço apropriado e vivido tem uma história - uma cultura que se sedimenta através do tempo. Assim, a reciprocidade pode se firmar como o fundamento para a consolidação das redes que se projetam num território. De certo modo, as redes funcionam como fluxos, cujos nós são ligados por meio dos códigos, e a materialidade de suas relações não se opõe aos 
aspectos sígnicos. A recorrência destes fluxos num dado espaço, para os quais os códigos e a reciprocidade são essenciais, criam linhas que configuram o território e desenham os mapas de pertencimento dos atores sociais.

Os subsídios conceituais sobre os quais se discorreu até esta parte permitirão entender as peculiaridades do caso analisado. A particularidade está no olhar que é lançado sobre os fenômenos da configuração do mercado de trabalho e da interação entre as empresas locais, sempre de uma perspectiva histórica e relacional que marca estes processos sociais.

\section{O estudo de caso: diferenças e semelhanças entre as redes sociais e as formas de reciprocidade em Veranópolis e arredores}

Localizado próximo a Bento Gonçalves, o município está no eixo Caxias do Sul-Porto Alegre, que se caracteriza por ser a região mais industrializada do Estado. Nos primeiros anos da colonização majoritariamente italiana e polonesas, ocorrida no fim do século XIX, os colonos desenvolveram a agricultura de base familiar como atividade principal, setor que se manteve importante mesmo após o início dos processos de industrialização e urbanização. A partir do crescimento da economia agrícola, setores industriais também se desenvolveram ao longo das décadas.

No Censo Demográfico de 2000, Veranópolis possuía 19.466 habitantes, dos quais $82,3 \%$ residiam na área urbana e $17,7 \%$ na área rural. Um dos aspectos mais marcantes da economia de Veranópolis é o número de microempresas. A pesquisa sobre cadastro de empresas do IBGE (1998) informa 1.173 empresas cadastradas com CNPJ sendo que $91,82 \%$ delas com até nove empregados. Dentre os ramos e setores da economia, pode-se enumerar os mais importantes: 
armas, calçados, artigos esportivos, microfusão ${ }^{6}$ e comerciantes de frutas.

Mais do que simplesmente acumulação de capital, havia outros fatores que se fazia necessário pesquisar para explicar a industrialização e a diversificação de atividades em Veranópolis. Uma das origens destas empresas está justamente nas redes de produção e trabalho construídas historicamente no tecido social local desde o período da economia colonial.

Em Veranópolis, redes sociais se estruturaram ao longo do tempo em torno de referenciais comuns, cujas trocas entre as pessoas envolviam ajudas, trabalho, parentesco, empréstimos. Essas redes só se tornaram maiores quando passou a ocorrer uma complexificação do mercado de trabalho e a mercantilização das relações de troca, sendo essas redes acessadas estrategicamente por atores sociais locais para a sua reprodução social e criação de novas formas de trabalho. Entretanto, a pesquisa mostrou que, apesar de suas origens comuns, as diferentes redes desenvolveram características próprias. Estas particularidades têm importância decisiva para o seu funcionamento e conseqüências fundamentais para a economia local, como será visto a seguir.

\section{O papel das redes na organização dos fruteiros}

Bastante conhecidos na região de Veranópolis, os comerciantes chamados de fruteiros são, na realidade, compradores e vendedores de diversos produtos, tais como hortaliças, legumes e, obviamente, frutas. A atividade tem início no município de Veranópolis a partir de meados dos anos 1950, quando um agricultor da localidade de Lajeadinho resolveu vender seus produtos agrícolas visitando outros lugares com seu veículo. O sucesso deste fez com que outros se prontificassem a imitá-lo, cada qual com sua produção. A partir 
do momento em que a atividade se expande e o dinheiro ganho é investido no próprio ofício, passaram a comprar a produção de outros e vender em locais cada vez mais distantes.

Atualmente, existem vinte e cinco fruteiros em Veranópolis e a maior parte deles já não cultiva nada. O comércio dos produtos é muito mais lucrativo, uma vez que já há diferenciação expressiva entre eles. Um grupo deles, a maior parte, possui caminhões pequenos e armazena os produtos na própria casa ou em depósitos menores. Vendem na cidade ou nos arredores. Existe um grupo intermediário, que chega a viajar pelo interior do Estado e tem depósitos com mais capacidade. Chama a atenção o fato de os maiores - um grupo não muito numeroso, mas que faz importação e exportação de frutas -, comercializarem em lugares distantes no Brasil e possuírem todo tipo de infra-estrutura para armazenamento e distribuição dos produtos.

Interessante é observar como o mercado dos fruteiros é organizado em função de suas relações e um misto de cooperação e concorrência se projeta entre eles. Quanto aos produtos, cada comerciante procura não "invadir" o espaço do outro, embora isto na prática seja impossível em alguns casos. Isso se manifesta no fato de que cada fruteiro se especializa num produto diferente (tomate, banana, mamão, cebola), ainda que comercialize outros também. Porém acaba acontecendo que a pauta de produtos demandados não é tão extensa e ocorrem as superposições. Neste caso, cada unidade então busca uma estratégia de venda diferenciada: uma rota para os caminhões, um tipo de comércio (de porta em porta ou distribuindo a outros atravessadores etc.).

Este comportamento não redunda na inexistência de conflitos, ao contrário, os atores sociais lidam com isto cotidianamente, embora discursivamente tentem não se manifestar de maneira direta. Existe uma tentativa sempre de declarar que o próximo é um cooperador, não alguém com quem se compete. O mais relevante é o 
fato da rede tecer-se com a cooperação acontecendo paralelamente à concorrência. Por exemplo, quando um fruteiro não tem um determinado produto no momento em que é demandado, ele busca o pedido em outro, que é (supostamente) seu concorrente. Para este tipo de trâmite, os entrevistados informaram haver regras claras entre eles, mas regras não escritas, o que constitui o jogo da reciprocidade (a regulação informal dos comportamentos). A idéia de uma construção social do mercado, tal como proposta por Bagnasco e Triglia (1993), manifesta-se na organização que possui o mercado regional e nas regras e formas de competição.

As relações entre os fruteiros adquirem uma conformação em rede, tal como Barnes (1987) e Mayer (1987) aludiram, não somente pelos recorrentes vínculos, mas também pelas suas diferenças na economia local. Alguns são aliados de fato, outros são "mais" concorrentes, dependendo do produto em que se especializam. Neste sentido, a organização do mercado não consegue ocultar as disputas comerciais, por isso as alianças amparam-se antes na esperança da retribuição.

No que diz respeito ao mercado de trabalho há uma questão fundamental que vem a ser a maneira como os novos empreendimentos surgem, e isto se manifesta também nas outras duas redes que serão analisadas a seguir. A rede sugere o desenho pelo qual o mercado de trabalho é "topografado", pois ela conecta pontos (nós) heterogêneos, que ocupam posições distintas no social. Os indivíduos acessam pessoas que acessam ainda outras e, neste processo, o primeiro pode obter seu emprego, num movimento semelhante ao analisado por Granovetter (1973). Depois de ter a ocupação, angariam experiência e conhecimento do ramo e neste momento a rede dos fruteiros se vê em face de um novo possível concorrente: aqueles empregados que trabalharam durante anos têm plena capacidade de empreender e possuir seu próprio negócio. O que é curioso é que, muitas vezes, os ex-empregados procuram 
não concorrer diretamente com seus ex-patrões, sinal de um ato de reciprocidade, como Caillé (1998a) sustenta, ou, na acepção de Gouldner (1960) sobre as normas da reciprocidade, não injuriar aqueles que não os injuriaram.

Entretanto, as relações em rede e as formas de reciprocidade não são apenas importantes para entrar no mercado de trabalho via indicação, estas relações constituem maneiras de instituir os empreendimentos. É no trabalho coletivo, na associação com conhecidos ou parentes, que as pequenas empresas conseguem ser criadas e estabilizadas. Portanto, as relações de reciprocidade, que redundam em confiança, são importantes, pois um indivíduo sozinho talvez não se lançasse em novos empreendimentos - cujo risco é desperdiçar os esforços. A conclusão mais importante sobre este aspecto é que as relações de proximidade são fundamentais quando os capitais econômicos são escassos.

É nesse sentido que se advoga o recurso da análise de redes sociais, porque o mercado de trabalho e o surgimento de novas empresas se dão por meio de vínculos pessoais. O mercado de trabalho pode, muitas vezes, funcionar como uma ampla rede que conecta empregados, empregadores, desempregados e conhecidos. Estes são ligados por laços, ora fortes, ora fracos e, para o caso dos fruteiros de Veranópolis, os novos empresários tecem o fio da rede que os liga aos empreendimentos em que anteriormente eram funcionários. A dinâmica se renova ininterruptamente, como o depoimento de um empregado do ramo: "os que mais queriam [empreender] são os meus filhos, eles gostariam de "botar" alguma coisa própria" (entrevistado, empregado de um comerciante de frutas).

E uma das empregadoras afirmou:

[...] talvez um deles [de seus funcionários] seja um pouquinho mais ambicioso e sonhe um pouquinho mais alto, o resto eu acho que não. Ele conhece bem o ramo e trabalha com meu marido há muitos anos. (entrevistada, comerciante). 
Assim, as pessoas procuram reunir sinergias para constituir novas empresas, isto é, relações de proximidade que serão úteis quando tiverem seus empreendimentos próprios. Wolf (2003) desenvolve a idéia de que nas sociedades complexas as estruturas informais, paralelas às burocráticas, podem ser tão centrais que essas alianças entre parentes, compadres e amigos se tornam o fundamento que possibilita as empresas. Portanto, acontece uma combinação de confiança nas relações de parentesco ou proximidade e dádiva mútua entre sócios - contribuições em forma de capital, trabalho e conhecimento para iniciar e manter a empresa.

É de tácita aceitação a condição de que apenas relações de reciprocidade não são suficientes para os novos empreendimentos. Mas o que as informações colhidas a campo mostram é que, mesmo que o capital econômico seja fundamental (conseguido na dispensa do empregado ou com um sócio), outros fatores são importantes para explicar esta dinâmica da economia local, como o conhecimento que os empregados obtêm do ramo. Por esta razão é que aqueles que foram empregados por anos de um comerciante fruteiro, procuram empreender no próprio ramo, ao invés de tentar a sorte em outro setor da economia. Um entrevistado salientou: "eu conhecia bem o ramo, trabalhei durante anos, e meu sócio conhecia bem como vender o produto, o tomate" (entrevistado, sócio e comerciante).

O que deve ser destacado é que a peculiaridade dos fruteiros e da rede construída por eles é que este círculo de relações prepara os indivíduos que aí interagem para serem comerciantes. Por isso, as informações sobre os mercados, as interações pessoais, o conhecimento dos preços e dos bons e maus pagadores são essenciais para o sucesso. Os laços de amizade e os vínculos são centrais para o acesso à rede, como enfatizou Wanderley (2002), e funcionam como suporte para os novos negócios. Do ponto de vista da construção social dos mercados, a reciprocidade aparece também entre os empreendimentos de fruteiros, pois entre eles se 
faz necessário construir relações de cooperação, mesmo tendo que administrar a concorrência.

As redes como vetores de conhecimento: as empresas de microfusão

As microfusões de Veranópolis são indústrias de fusão de aços que fornecem peças de alta perfeição de detalhes para diversos ramos da metalurgia e da mecânica. Existem no município e nos arredores cinco empresas, todas elas consideradas de médio a grande porte, e outras tantas iniciativas de pequenos empreendimentos que realizam trabalhos para estas empresas maiores. Elas terceirizam partes do processo de fabricação industrial para pequenas indústrias, como as matrizarias (oficinas e fábricas produtoras de matrizes ${ }^{7}$ para fundição de peças) e os fornecedores de máquinas.

Esta rede de indústrias teve início a partir de uma única empresa, a Boito, que, no começo de seu funcionamento, fabricava apenas armas. Desde o tempo da constituição da indústria de bases artesanais, as relações de reciprocidade, as trocas e a proximidade entre os antigos colonos eram fundamentais, conforme o relato:

O sr. Barbieri ia na oficina do avô pra ajudá-lo da fabricação da arma e ele colocava a sua filha mais velha na lavoura no lugar do seu Barbieri para trabalhar. E depois, se associou também à família Dal'Agnol. (entrevistada, empregada).

A empresa de armas cresceu e surgiu a necessidade de peças específicas, o que fez os donos abrirem uma outra unidade no município apenas para a microfusão. A rede, neste caso, é particularmente curiosa, pois parece desenhar uma espiral: vários empreendimentos surgidos ao longo do tempo a partir de um único, e outros que se desmembraram destes, veja-se o relato: 
A microfusão de Veranópolis é a "mãe" de todas as microfusões do Rio Grande do Sul e de Santa Catarina. Todos os funcionários trabalharam ou saíram de dentro da MicroVera e montaram as suas empresas. (entrevistado, empregado).

Neste processo aparece a competição, mas que é também diluída em função das fatias de mercado e da especialização que toca a cada empresa. Tal como no caso dos fruteiros, o mercado é construído social e historicamente, como analisaram Bagnasco e Triglia para a Terceira Itália, mas isso não significa que não haja conflitos. Como a indústria que iniciou o ramo é quase um símbolo do município, torna-se fácil encontrar julgamentos depreciativos sobre aqueles que dela saíram e se tornaram seus concorrentes. Ocorre que, na realidade, os novos empreendimentos tornaram a região um pólo deste tipo de indústria, bem como a concorrência é apenas relativa: os mercados para venda são muito diversificados.

O mercado de trabalho ligado a esta rede tem uma peculiaridade que ajuda a explicar a concorrência entre as empresas. O saber-fazer da fábrica é muito específico e não há quase escolas que propiciem a formação de técnicos, assim o conhecimento deve ser aprendido pelos empregados no próprio chão de fábrica. Os recém-contratados são alocados em setores de menor complexidade do trabalho e, aos poucos, vão ascendendo, conforme desempenho e oportunidade. $\mathrm{O}$ que vem a ser um diferencial para o trabalhador é que ele, geralmente, entra na fábrica sem conhecer o ofício, e pode sair com uma profissão e experiência. Por conseguinte, no momento em que certo empregado tiver a chance de empreender, com capital econômico obtido nas mais variadas formas - sobretudo por meio das relações de reciprocidade com prováveis sócios - poderá ter sua própria empresa. Pode parecer ingênuo, mas uma das maiores indústrias da região iniciou-se desta forma, com apenas dois sócios, duas máquinas e nenhum empregado. Na pesquisa de campo, observouse também que as pequenas matrizarias espalhadas pelo município (inclusive nas áreas rurais) também crescem significativamente. 
Esse é um dos resultados desta formação reticular: o aprendizado é coletivo e o saber-fazer se difunde rapidamente. A reciprocidade, no caso analisado, se processa a partir da participação dos indivíduos nas esferas de aprendizado, no interior da indústria. Para conhecer o modus operandi, é preciso "pertencer à rede", assim ele obtém conhecimento suficiente depois de alguns anos de experiência e do saber que lhe é transmitido. As relações se estendem para além dos empregados, incluindo os que procuram empregos e também os que não buscam (atuam apenas como fontes de informação), oferecendo uma clara configuração de rede, tal qual aparece nos trabalhos de Barnes (1987) e de Mayer (1987). Conforme o depoimento:

O que fazíamos anteriormente era buscar familiares, parentes, amigos, conhecidos [para trabalhar]. Hoje, o que a gente faz? Nós buscamos familiares, parentes, amigos e conhecidos. São indicações. (entrevistado, empregado).

Estes contratados serão os que mais terão oportunidades de colocar negócios próprios no futuro e a existência da concorrência pode ser vista como cooperação se se observa a escala das empresas. As grandes indústrias buscam as pequenas ou médias para que estas realizem parte da produção, num claro esquema de terceirização. E os terceirizados se alimentam desta dinâmica empresarial do território, que é condição para o seu desenvolvimento. Portanto, a existência das diversas indústrias e das redes cria um sistema produtivo local que é próspero para o sistema de empregos da região.

Mas é preciso salientar que nem todos adquirem recursos materiais e sociais para ter sua empresa. Uma ampla maioria permanece no "chão de fábrica", apenas assistindo aos casos de sucesso. Pelo menos em parte, os conflitos sociais locais se dão por um confronto entre lógicas distintas, isto é, entre os que almejam ascender socialmente, tal como os casos de empreendedores de 
sucesso, e os que gostariam de também realizar, mas não aceitam a submissão, a fidelidade à empresa e o trabalho extenuante.

A título de comparação com a rede dos fruteiros, a reciprocidade no ramo da microfusão também adquire uma forma específica. Aqueles que possuem o saber técnico são capazes de transmiti-lo para os novatos na medida em que estes trabalham nas indústrias. Isso é o que lhes permite angariar conhecimento e ascender profissionalmente dentro da empresa. Por esta razão, podem agenciar negócios próprios quando obtiverem recursos suficientes, que é conseguido pelas relações de proximidade. Este é o efeito multiplicador na economia local e, via condutas de reciprocidade, a rede conecta pessoas ao mercado de trabalho (que na realidade é uma rede de laços sociais, inclusive de trabalho) e empresas a um sistema local.

Redes e hierarquias: o caso das indústrias de calçados e bolas

O ramo das indústrias de calçados e artigos esportivos, principalmente bolas, é composto também por unidades de tamanhos diversos. Veranópolis comporta cerca de doze indústrias do ramo, que se somam aos diversos ateliers de costura difundidos pelas áreas urbana e rural do município. A origem das fábricas reside na primeira empresa de fabricação de artigos de couro e bolas que Gerônimo Todeschini e Benvenutti Dal Ponte fundaram entre os anos 1920 e 1930. Até os dias de hoje, a empresa Dal Ponte é uma das maiores da região, juntamente com a São Paulo Alpargatas, indústria que veio do centro do país se instalar em Veranópolis no final dos anos $70 .^{8}$

O ramo das indústrias de calçados e artigos esportivos é extremamente dinâmico na economia local, ocupando mão-de-obra não apenas do município, mas da região como um todo. Apenas para quantificar, as duas maiores empresas empregam cerca de 1.800 trabalhadores diretamente, sem contabilizar as fábricas-satélite. 
O esquema de terceirização da produção é uma característica muito mais importante neste ramo. Segundo Schneider (2002, p. 77), foi nos anos 90 que o sistema de subcontratação se ampliou, o que proporcionou o surgimento de outras empresas de artigos esportivos no local (fábricas cujo tamanho varia de pequeno a médio). As operações de subcontratação é o que liga empresas grandes, médias e pequenas, fazendo surgir um sistema de terceirização que funciona em rede. As grandes fábricas buscam direcionar partes do processo produtivo para as pequenas. E as formas de vínculos entre as diferentes empresas são inscritas nos princípios de reciprocidade, visto que é geralmente na figura de um gerente ou dono que as alianças são realizadas.

Pelo seu tamanho e pelo tipo de atividade ser intensivo no uso de força de trabalho, as empresas de calçados e bolas acabaram atraindo não apenas a mão-de-obra local e regional, como migrantes de outras regiões do Rio Grande do Sul, de modo semelhante ao estudado por Schneider (1999) para as empresas de calçados do vale dos Sinos. Muitos migrantes que se empregam na condição de proletários, trabalham por um período e abandonam o emprego, por não estarem de acordo com o nível de remuneração. Por este motivo é que muitos dos operários, tanto os locais como os que vêm de fora, não se sentem atraídos por trabalhar nas fábricas de calçado/artigos esportivos. A diferença é que para os primeiros essa ocupação pode ser uma fase da carreira, uma experiência ou uma maneira de ser indicado a outro emprego, enquanto os últimos não pertencem às extensas teias de sociabilidade e para eles é mais inoportuno se submeter a isto.

Parte dos trabalhadores ocupados no ramo e oriundos da região são filhos ou cônjuges de agricultores familiares. Aqui há uma característica que vale a pena ser descrita: o trabalho a domicílio. É usual que os trabalhadores realizem a costura do couro, que pode ser de bolas ou calçados. Fenômeno já analisado por Schneider (1999) 
no pólo de produção de calçados na região de Novo Hamburgo, em Veranópolis ele funciona da seguinte maneira. A empresa contrata uma pessoa da família - uma mulher, na maior parte dos casos para fazer costura em seu próprio domicílio, mas como há volume de produção a ser entregue pela pessoa à fábrica, a produtividade da trabalhadora contratada deve ser alta. Então, outros membros da família acabam ajudando, mas oficialmente as empresas só realizam o contrato de trabalho através da mulher.

Mais perceptível que nas outras duas redes anteriormente analisadas, esta se caracteriza por uma mais expressiva concorrência entre as empresas. Nos outros casos, a cooperação e a reciprocidade regulavam o mercado e geravam uma rede de aliados. Nesta rede, as subcontratações parecem formar grupos, manifestando características de exclusividade em certos casos. Este caráter não sugere que os mecanismos de reciprocidade não funcionem, no entanto as alianças específicas podem estruturar uma hierarquia vertical: as duas grandes empresas realizam relações singulares com cada terceirizada - ou rede de terceirizadas. Aqui os regimes de reciprocidade se processam através da confiança que os grandes industriais depositam nos menores. Neste sentido, são relações que pedem exclusividade e, mais que qualquer outra, fazem emergir redes de poder.

Entretanto, as pequenas fábricas e os ateliers formam outro tipo de configuração entre si, evidentemente, entre aqueles que são parceiros. Suas interações adquirem um formato horizontal, indicando uns aos outros quando não podem aceitar os pedidos, ou compartilhando demandas. A indicação de mercados, a aposta na confiança e na esperança da retribuição, como Caillé formulou, recria a reciprocidade. Isso pode vir a minimizar o sentimento de competição e a reforçar o de cooperação, segundo o relato: "eu tenho mais três concorrentes. Eu não gosto de usar o termo "concorrente". Eu, pelo contrário, eu me dou bem com todos eles" (entrevistado, empresário). 
Tal como analisado nas redes de fruteiros e da microfusão, o setor não foge à regra no que diz respeito ao surgimento das novas empresas, ou seja, na maior parte dos casos, os donos são exempregados do setor de calçados e artigos esportivos, particularmente oriundos das duas grandes fábricas: Dal Ponte ou Alpargatas. Geralmente, ex-chefes de setores nas empresas em que trabalhavam, têm conhecimento e necessitam conseguir capital para investir, que pode vir através de alguém de confiança. Dessa maneira, estão presentes os fatores fundamentais para a consolidação da fábrica: as relações de reciprocidade, que operam na junção de capital econômico, o conhecimento e a confiança entre os associados.

Um dos entrevistados iniciou sua empresa por meio da parceria com um colega de trabalho. Trabalhando juntos num mesmo setor da fábrica, certo dia surgiu a idéia de constituir uma empresa que realizasse a terceirização para a indústria na qual trabalhavam. Para tal feito, era necessário participar da rede de trabalho e ter as informações corretas para efetivar a empresa. As conexões - como sugere Mayer (1987) - são essenciais para as estratégias de ação em rede e isto se materializou em obter confiança da empresa na qual trabalhava, como também na relação com seu sócio. E, apenas para dar uma idéia de como os recursos financeiros são importantes, mas não determinantes, no caso deste empresário a situação econômica era difícil:

A gente não tinha dinheiro nenhum. Não tinha dinheiro nem pra começar e registrar a firma. E a gente fez um financiamento no banco. Conseguimos fazer o financiamento e compramos uma máquina. Até o dinheiro pra abrir a firma foi emprestado, não tinha nada, começamos do zero. E a gente começou. Colocamos a máquina em casa. (entrevistado, empresário).

Desse modo, a rede de empresas, que se materializa nas relações de trabalho e de reciprocidade, produziu um setor da economia bastante dinâmico. Nas indústrias de calçados e artigos esportivos a 
reciprocidade possui sentidos distintos. Ela tem um caráter vertical, porque as duas grandes empresas são responsáveis pela alocação de trabalho da significativa parte das fábricas menores. A verticalidade e a clara relação de poder também se verificam entre as empresas médias e pequenas. Portanto, a confiança da subcontratação é o que sustenta a reciprocidade e o regime de obrigações. Contudo, conforme se observou antes, entre as pequenas fábricas e ateliers (por conjugarem esforços) a rede se projeta horizontalmente.

\section{Considerações finais}

Procurou-se mostrar neste trabalho a importância das relações de reciprocidade para a formação de redes sociais de trabalho no município de Veranópolis e seus arredores. As redes se desenham no território (elas criam territorialidades), realizando-se por meio de atores diversos. Pode-se dizer que as mudanças empreendidas por meio das redes são constantes na dinâmica econômica e social, pois esta teia de relações é um fazer-se ininterrupto, e a textura das redes sempre está na eminência de transformações e da reinvenção das territorialidades.

Embora tenham uma origem social comum, na qual as relações de reciprocidade exercem um efeito expressivo, as redes analisadas apresentam distintas características e configurações. Na rede dos fruteiros, a reciprocidade está vinculada à maneira como eles se tornam comerciantes, ou seja, como conhecem os mercados, de que maneira acessam informações sobre produtos, clientes, fornecedores e rotas de comercialização. Para isto, são necessárias relações de proximidade entre os atores sociais do ramo.

Na rede que liga os atores sociais das indústrias de microfusão, o essencial é o saber técnico "acumulado" no período em que os operários trabalham nas empresas. Por entrarem nas fábricas, na 
maior parte das vezes, sem experiência de trabalho, o conhecimento que lhes é transmitido adquire sentido de dádiva. Esta pode ser retribuída quando os trabalhadores permanecem em seus empregos e se identificam com a empresa. Entretanto, ocorre também entre os que se tornam novos empreendedores do ramo e procuram não se tornar concorrentes diretos (nos mesmos produtos) de seus antigos patrões, embora estes últimos nem sempre interpretem dessa maneira.

Nas indústrias de calçados e artigos esportivos, o fenômeno é distinto, visto que há inúmeras fábricas na região que se vinculam por meio da terceirização da produção. A reciprocidade se apresenta de duas formas: na relação vertical entre as fábricas grandes e as menores, com a confiança na terceirização da produção e o poder de estabelecer alianças exclusivas; na relação horizontal entre os pequenos empresários, confiança na subcontratação e parceria quando suas unidades não podem responder às demandas das empresas maiores.

Pode-se afirmar que a regulação da concorrência e a estrutura dos mercados são resultado das ações dos atores nas redes a que pertencem; portanto, os vínculos e as posições sociais destes são basilares para o funcionamento dos mercados. O esquema que hibridiza competição e cooperação é constituinte da dinâmica dessas relações, fator que vem a fornecer a espessura cultural existente no local, uma das instâncias pelas quais se percebe a maneira como o mercado foi construído social e historicamente.

É preciso observar que redes de reciprocidade não conduzem obrigatoriamente as sociedades ao desenvolvimento. A idéia não é menosprezar o papel dos recursos econômicos, do conhecimento e do acesso a tecnologias, também responsáveis pelo sucesso de pessoas, empresas e redes. No entanto, o argumento é que os atores sociais analisados compartilham recursos sociais e simbólicos no 
território, que são essenciais para gerar efeitos benéficos do ponto de vista social e econômico. Deste modo, o conjunto de relações em rede é responsável pelo dinamismo do mercado de trabalho e pela diferenciação da economia local. Este processo se sustenta na teia de laços que distintos atores constroem, uma vez que articula empregadores, empregados, desempregados e conhecidos no tecido social local. Assim, novos empregos e empreendimentos passam a existir ao longo do tempo, o que vem a exercer efeitos diretos para a multiplicação das atividades e para o desenvolvimento do território como um todo.

\section{Notas}

1 Seria um percurso teórico muito extenso para desenvolver aqui as diferentes interpretações sobre a dádiva e a reciprocidade na teoria social, desde Lévi-Strauss a Bourdieu, passando por Godelier na vertente francesa, como também as apropriações com ênfases mais individualistas dos teóricos anglo-saxões (Gouldner, Wolf e outros).

2 Caillé (2002) observa que a dádiva é mais ampla, pois pode abranger atos como a dádiva das palavras (elogios, afetos). Mas isso só vem a reforçar a objetividade da ação. Elas representam, semelhante ao que foi proposto por Peirano (2001) quando inspirada nos escritos de Austin, que "dizer é fazer".

3 Para este assunto, ver também Marques (2000).

4 Caillé (1998a) chama a atenção que Malinowski (2003) já tinha observado o fenômeno das redes. Quando nas ilhas Trobriand examinou o kula, Malinowski percebeu que havia uma rede pela qual ele se realizava. O kula seria uma circulação que aconteceria através de "dádivas simbólicas de bens preciosos", um grande círculo de comércio. Sob a ótica de Caillé (1998a, p. 18), rede é “[...] conjunto das pessoas em relação às quais a manutenção de relações [...] permite conservar e esperar confiança e fidelidade [...]" e estas são criadas por atores sociais “[...] a partir da aposta da dádiva e da confiança [...]”. 
5 A dificuldade de analisar reciprocidade e redes interpessoais no capitalismo parece estar na incapacidade de este sistema social estabilizar os laços sociais. Em vários registros, Deleuze contrapõe o capitalismo a todas as outras formações sociais porque este se baseia na desterritorialização e na decodificação de códigos tradicionais. O capitalismo se alimentaria desta constante desterritorialização, mudança dos códigos sociais e das relações estabelecidas. Isto se aproximaria da interpretação de Polanyi em ao menos um aspecto: o capitalismo para Polanyi é a instituição dos mercados auto-regulados. Ocorre que o próprio Deleuze chama a atenção de um movimento contrário, a reterritorialização, criação dos novos códigos. Da mesma maneira que este criticou Clastres por haver presumido que os mecanismos contra o surgimento do Estado desaparecem nas sociedades que instituem o Estado (ver, por exemplo, o texto de Goldman, 1999), no capitalismo o processo de reterritorialização seria uma resistência, e a dádiva e as formas de reciprocidade tentativas de novas estabilizações e novos códigos, mesmo sabendo que o sistema eventualmente irá desterritorializá-los novamente.

6 Microfusão é a fusão de aços cujo processo tem por objetivo projetar e moldar peças que necessitam perfeição nos detalhes e ligas de metais diversos.

7 Matrizes são as peças únicas utilizadas na fabricação dos componentes em série. As empresas de microfusão encomendam as matrizes, que são feitas em aço e em cera pelas matrizarias.

8 Até o momento da realização da pesquisa, a empresa São Paulo Alpargatas mantinha sua unidade no município, no entanto soube-se que recentemente fechou suas portas. No local está em andamento o projeto de instalação de uma indústria de móveis. Acredita-se que este fato não seja prejudicial aos resultados do artigo.

The economic web: social network and reciprocity relations inside local development

Abstract: The paper analyses social networks from a point of view that highlights reciprocity relations. Applying a case study 
in Veranópolis municipality, Rio Grande do Sul, the paper find out to understand the importance of reciprocity relations in the constitution of labour networks engaged to trading, micro fusion industries, shoes and sporting goods industries. The analysis aims to demonstrate that even though the existence of a common social origin, labour networks show different characteristics that refer to labour forms, modes of operation and competition regulation between the entrepreneurships. In this study, the set of network relations is responsible for providing dynamism to the labour market as well as for the differentiation of the local economy, articulating actors who constitute social ties and exercise relevant effects to territorial development as a whole.

Keywords: social networks, reciprocity, territory.

\section{Referências}

ABRAMOVAY, Ricardo. Entre Deus e o Diabo: mercados e interação humana em Ciências Sociais. Tempo Social: Revista de Sociologia da USP, v. 16, n. 2, p. 35-64, 2004.

BAGNASCO, Arnaldo; TRIGLIA, Carlo. La construction sociale du marché: le defi de la Troisieme Italie. Paris: Julillet, Editions de l'ENSCachan, 1993.

BARNES, John A. Redes sociais e processo político. In: FELDMANBIANCO, B. (Org.). Antropologia das sociedades contemporâneas: métodos. São Paulo: Global, 1987. p.159-193.

BOTTAZZI, Gianfranco. Le développement local ou la remontée du local: considérations pour une définition de l'espace local? In: COLLOQUE NOUVEAUX DYNAMISMES INDUSTRIELS ET ÉCONOMIE DU DÉVELOPPEMENT. Grenoble: IREPD, 1994. p. 423-447. (Série Actes de Colloques)

BOURDIEU, Pierre. Razões práticas: sobre a teoria da ação. São Paulo: Papirus, 1996a. 
BOURDIEU, Pierre. Marginalia: algumas notas adicionais sobre o dom. Mana: Estudos de Antropologia Social, v. 2, n. 2, p. 7-20, 1996b.

BOYSSEVAIN, Jeremy. Apresentando amigos de amigos: redes sociais, manipuladores e coalizões. In: FELDMAN-BIANCO, Bela (Org.). Antropologia das sociedades contemporâneas: métodos. São Paulo: Global, 1987. p. 159-193.

CAILLÉ, Alain. Nem holismo nem individualismo metodológicos: Marcel Mauss e o paradigma da dádiva. Revista Brasileira de Ciências Sociais, v. 13, n. 38, p. 5-38, 1988a

. Don et association. La Revue du MAUSS, Paris, n. 11, p. 75-83, $1^{\text {er }}$ Sem. $1988 b$

. A dádiva das palavras: o que dizer pretende dar; dádiva e associação. In: MARTINS, Paulo Henrique (Org.). A dádiva entre os modernos: discussão sobre os fundamentos e as regras do social. Petrópolis: Vozes, 2002. p. 99-135.

CASTELLS, Manuel. A sociedade em rede. São Paulo: Paz e Terra, 1999.

FLICK, Uwe. Uma introdução à pesquisa qualitativa. 2. ed. Porto Alegre: Bookman, 2004.

GOLDMAN, Marcio. O que fazer com selvagens, bárbaros e civilizados? In: . Alguma Antropologia. Rio de Janeiro: Relume Dumará, 1999. p. 77-82. (Coleção Antropologia da Política, 7).

GOULDNER, Alvin W. The norm of reciprocity: a preliminary statement. American Sociological Review, v. 25, n. 2, p. 161-178, 1960.

GRANOVETTER, Mark. The strength of weak ties. American Journal of Sociology, v. 78, n. 6, p. 1360-1380, 1973.

. Economic action and social structure: the problem of embeddedness. American Journal of Sociology, n. 91, p. 481-510, 1985.

LÉVI-STRAUSS, Claude. Introdução à obra de Marcel Mauss. In: MAUSS, Marcel. Sociologia e Antropologia. São Paulo: Edusp, 1974. v. 2, p. $9-48$. 
LONG, Norman. Development sociology: actor perspectives. London: Routledge, 2001.

LOWE, Philipe et al. Networks in rural development: beyond exogenous and endogenous models. In: PLOEG, Jan Douwe van der; DIJK, Gerrit van (Ed.). Beyond modernization: the impact of endogenous rural development. Assen: Van Gorcum, 1995. p. 87-105.

MARQUES, Eduardo C. Estado e redes sociais: permeabilidade e coesão nas políticas urbanas no Rio de Janeiro. Rio de Janeiro: Revan; São Paulo: Fapesp, 2000.

. Redes sociais e poder no Estado brasileiro: aprendizado a partir das políticas urbanas. Revista Brasileira de Ciências Sociais, v. 21, n. 60 , p. $15-41,2006$.

MAUSS, Marcel. Ensaio sobre a dádiva: forma e razão da troca nas sociedades arcaicas. In: Sociologia e Antropologia. São Paulo: Edusp, 1974. v. 2, p. 49-209.

MAYER, Adrian C. A importância dos quase grupos no estudo das sociedades complexas. In: FELDMAN-BIANCO, Bela (Org.). Antropologia das sociedades contemporâneas: métodos. São Paulo: Global, 1987. p. 127-158.

MALINOWSKI, Bronislaw. Crime e costume na sociedade selvagem. Brasília: Ed. da UnB; São Paulo: Imprensa Oficial do Estado, 2003.

MIOR, Luiz Carlos. Desenvolvimento rural: contribuição da abordagem das redes sociais e sociotécnicas. In: SCHNEIDER, Sergio (Org.). A diversidade da agricultura familiar. Porto Alegre: Ed. da Universidade (UFRGS), 2006. p. 268-293.

MURDOCH, Jonathan. Networks: a new paradigm of rural development? Journal of Rural Studies, v. 16, n. 1, p. 407-419, 2000.

PEIRANO, Mariza. Rituais como estratégia analítica e abordagem etnográfica [Prefácio]. In: PEIRANO, Mariza (Org.). O dito e o feito: ensaios de antropologia dos rituais. Rio de Janeiro: Relume Dumará, 2001. p. 7-14. 
POLANYI, Karl. A grande transformação: as origens da nossa época. 2. ed. Rio de Janeiro: Campus, 2000.

. La economía como actividad institucionalizada. In: POLANYI, Karl et al. (Org.). Comercio y mercado en los impérios antiguos. Barcelona: Labor Universitaria, 1976. p. 289-315.

RADCLIFFE-BROWN, Alfred Reginald. Structure and function in primitive society: essays and addresses. London: Cohen and West, 1952.

RADOMSKY, Guilherme Francisco Waterloo. Reciprocidade, redes sociais e desenvolvimento rural. In: SCHNEIDER, Sergio (Org.). A diversidade da agricultura familiar. Porto Alegre: Ed. da Universidade (UFRGS), 2006, p. 104-133.

SABOURIN, Eric. Dádiva e reciprocidade nas sociedades rurais contemporâneas. In: ENCONTRO NORTE E NORDESTE DE CIÊNCIAS SOCIAIS, 11., 2003, Aracajú. Anais... Aracajú: UFS, 2003. v. 1, p. 1-26. [Fotocópia].

SCHERER-WARREN, Ilse. Redes sociais: trajetórias e fronteiras. In: DIAS, Leila Christina.; SILVEIRA, Rogério Leandro Lima. (Org.). Redes, sociedades e territórios. Santa Cruz do Sul: Edunisc, 2005. p. 29-50.

SCHNEIDER, Sergio. Agricultura familiar e industrialização: pluriatividade e descentralização industrial no Rio Grande do Sul. Porto Alegre: Ed. da Universidade (UFRGS), 1999.

- Dinâmica local e territorial do desenvolvimento rural no Rio Grande do Sul: um estudo de caso no município de Veranópolis na Encosta Superior da Serra do Nordeste (Relatório técnico de pesquisa). Porto Alegre, 2002.

WANDERLEY, Fernanda. Avanços e desafios da Nova Sociologia Econômica: notas sobre os estudos sociológicos do mercado. Sociedade e Estado, Brasília (DF), v. 17, n. 1, p. 15-38, 2002.

WOLF, Eric R. Parentesco, amizade e relações patrono-cliente em sociedades complexas. In: FELDMAN-BIANCO, Bela; RIBEIRO, Gustavo Lins (Org.). Antropologia e poder: contribuições de Eric R. Wolf. Brasília: Ed. da UnB; São Paulo: Imprensa Oficial do Estado, 2003. p. 93-114. 